\title{
Modification of optical properties of 2,5-bis(2-benzoxazolyl)hydro- quinone in opal photonic crystals
}

\author{
${ }^{1}$ Moiseyenko V., ${ }^{1}$ Dergachov M., ${ }^{2}$ Abu Sal B. and ${ }^{1}$ Yevchik A. \\ ${ }^{1}$ Oles Honchar Dnipropetrovsk National University, 72 Gagarin Ave., 49010 \\ Dnipropetrovsk, Ukraine, e-mail: vnmois@yandex.ru \\ ${ }^{2}$ Tafila Technical University, P. O. Box 40, Al-Eis 66141, Tafila, Jordan, \\ e-mail: bilal_abu@hotmail.com, abusal@ttu.edu.jo
}

Received: 16.09 .2013

\begin{abstract}
We study angular dependences of the reflection and fluorescence spectra for the synthetic opal infiltrated with a photo-reactive substance, 2,5-bis(2-benzoxazolyl)hydroquinone (BBHQ). The peak shift observed in the reflection spectra with increasing incidence angle of light is satisfactorily described by the Bragg diffraction law if the effective dielectric constant of the composite obtained by us is taken to be $\varepsilon_{\text {eff }}=2.10$. A suppression of fluorescence inside the stop-band and an increase in the shorter-wavelength fluorescence intensity are identified. The latter effect is explained by increasing role of radiative transitions through the surface states and impurity levels. The concentration of surface states increases essentially for the BBHQ embedded in the opal pores, and the impurity levels are formed by BBHQ molecules with substituted hydroxyl groups or with modified benzazole rings.
\end{abstract}

Keywords: opal photonic crystals, fluorescence, excited state intramolecular proton transfer

PACS: $78.55 . \mathrm{Kz}+42.70 . \mathrm{Qs}$

UDC: 535.361

\section{Introduction}

Recently considerable attention has been given to technology and investigations of regular 2D or $3 \mathrm{D}$ structures, for which the modulation period of the dielectric constant is of the order of light wavelength. An energy gap referred to as a photonic bandgap may be formed in the photonic spectrum of such structures along all spatial directions, depending on the type of their spatial symmetry and relations between the dielectric constants of constituent substances [1]. The structures revealing this property are usually called photonic crystals [2]. Availability of permitted and forbidden photonic bands in the photonic crystals imposes a series of novel optical phenomena interesting from both the fundamental viewpoint and numerous applications. Primarily, the photonic crystals are materials that enable controlling the characteristics of spontaneous emission within a wide range $[3,4]$. Synthetic opal composed of monodisperse $\mathrm{SiO}_{2}$ globules is widely used as a basic material for manufacturing the photonic crystals. Notice that gaps (so-called pseudogaps or stop-bands) are also available in the photon spectrum of the initial synthetic opal, though only along certain spatial directions [5]. These structures are very suitable for filling their interglobular space with active substances, which serve as peculiar light sources. At present, laserdye molecules, rare-earth ions and semiconductor nanocrystals usually serve as typical fillers in the synthetic opals [6-11].

The present article deals with preparations and studies for the optical properties of the synthetic opal whose pores are filled with a photo-reactive substance termed as 2,5-bis(2-benzoxa- 
zolyl)hydroquinone and abbreviated hereafter as BBHQ. Our aim is to detect the changes caused by the size effects and the photonic crystal structure. The interest in photo-reactive substances is primarily stimulated by intramolecular proton transfer occurring under ultraviolet illumination. It is known that this transfer represents one of fundamental reactions taking place in many elementary chemical and biological processes. Besides, promising possibilities for creating highperformance light emitting diodes and laser diodes, liquid-based lasers with ultra-short pulses, and bistable optical storage cells have been demonstrated with the materials mentioned above [12-15]. Preliminary studies of the fluorescence spectrum for the BBHQ embedded in the film synthetic opal have been performed in the work [16] under excitation out of the fundamental absorption bands. To the best of our knowledge, no systematic studies of the fluorescence of photo-reactive substances placed in the synthetic opal pores have been reported in the literature.

\section{Samples and experimental setup}

Samples of initial bulk synthetic opals were obtained using natural sedimentation of monodisperse $\alpha-\mathrm{SiO}_{2}$ globules synthesized with a Stöber's method [17]. Close-packed hexagonal globular layers perpendicular to direction of sedimentation form a face-centred cubic lattice structure with a preferred [111] direction [18]. To eliminate residuals of water and organic compounds from the opals, we dried for two days the precipitates obtained in the air, and then annealed them at $125^{\circ} \mathrm{C}$ for $1 \mathrm{~h}$ and at $800^{\circ} \mathrm{C}$ for $2 \mathrm{~h}$. The average dimensions of the bulk opals were $1.0 \times 1.0 \times 0.5 \mathrm{~cm}^{3}$.

A polycrystalline BBHQ powder was used as a starting material for infiltrating the initial opals. The infiltration was performed by repeatedly soaking the opal samples into a saturated hexane-BBHQ solution (at the BBHQ concentration of $10^{-4} \mathrm{M}$ ), and then drying them in the air. Of all solvents (hexane, heptane, and cyclohexanol) tested by us, the hexane was selected as it had the least effect on the fluorescence spectrum of BBHQ.

The absorption spectrum of the polycrystalline BBHQ was measured using a Shimadzu UV-3100 spectrophotometer (the spectral range of $270-650 \mathrm{~nm}$; the room-temperature conditions). Though we did not measure directly the thickness of the powder layer, it was adjusted so to correspond to the optical density of about 1.0. The reflection and fluorescence spectra of the opal infiltrated with BBHQ were measured in the range of $380-650 \mathrm{~nm}$ for different light propagation direction angles with respect to the direction [111] of opal growth. When measuring the reflection spectra, a radiation of incandescent lamp was used. The fluorescence of an 'opal-BBHQ' system in the back-scattering geometry was excited over the spectral region of fundamental absorption in the polycrystalline BBHQ. We used a continuous-wave radiation of a laser diode $(407 \mathrm{~nm}$; the average power of $60 \mathrm{~mW}$ ), and a pulsed radiation of a $337 \mathrm{~nm}$ nitrogen laser LGI-21 (the pulse frequency rate $100 \mathrm{~Hz}$ and the average power of $3 \mathrm{~mW}$ ). The most of the spectra thus obtained were analyzed using an upgraded spectrometer based on a double monochromator DFS-12. The radiation from the samples was collected by a lens with the aperture less than $0.17 \pi \mathrm{sr}$. In case of the nitrogen laser, a spectral complex KSVU-5 was used, with a recording system based on a standard CAMAC. In each of these cases, the optical signal was detected in a photon-counting mode with accumulation.

\section{Results and discussion}

\subsection{Characterization of opals infiltrated with $B B H Q$}

When characterizing our samples, we used the reflection spectra. Fig. 1 shows the reflection spectra measured under different conditions and normalized to the maximum reflection coefficient 
values. The diameters $D$ of the globules were determined following from the positions $\lambda_{m}$ of the reflection peaks in the corresponding spectra taken for the initial opal. This was done using the Bragg's law,

$$
\lambda_{m}(\theta)=2 d \sqrt{\varepsilon_{e f f}-\sin ^{2} \theta} .
$$

In Eq. (1), $\theta$ denotes the angle of incidence of a light beam on the system of $\{111\}$ planes, $d$ the interplanar distance, $D=d \sqrt{3 / 2}$, and $\varepsilon_{\text {eff }}$ the effective dielectric constant. The latter is defined by the dielectric constants $\varepsilon_{i}$ of the substances that form the composite, and the volume part $f_{i}$ of these substances:

$$
\varepsilon_{\text {eff }}=0.74 \cdot \varepsilon_{\mathrm{SiO}_{2}}+\sum_{i} f_{i} \cdot \varepsilon_{i}, \quad \sum_{i} f_{i}=0.26 .
$$

In case of the initial opal $\left(\varepsilon_{\mathrm{SiO}_{2}}=2.16, \varepsilon_{\text {air }}=1, \theta=7^{\circ}\right.$, and $\lambda_{m}=590 \mathrm{~nm}-$ see curve 1 in Fig. 1), we obtain the following parameters: $\varepsilon_{\text {eff }}=1.86, d=216 \mathrm{~nm}$, and $D=265 \mathrm{~nm}$.

After the opal is infiltrated, the reflection band for the same incidence angle shifts towards longer-wavelength region (see curve 2 in Fig. 1), thus indicating an increase in $\varepsilon_{\text {eff }}$ as a result of filling in the interglobular space with the BBHQ substance. A diffractive nature of the reflection band in this case is confirmed by a good agreement between the experimental positions of the reflection peaks and the corresponding values calculated with Eq. (1) at $\varepsilon_{\text {eff }}=2.10$ (see curves 2-5 and labels in Fig. 1). We could not estimate the degree of pore filling using Eq. (2), due to a lack of $\varepsilon_{B B H Q}$ data for the visible spectral range.

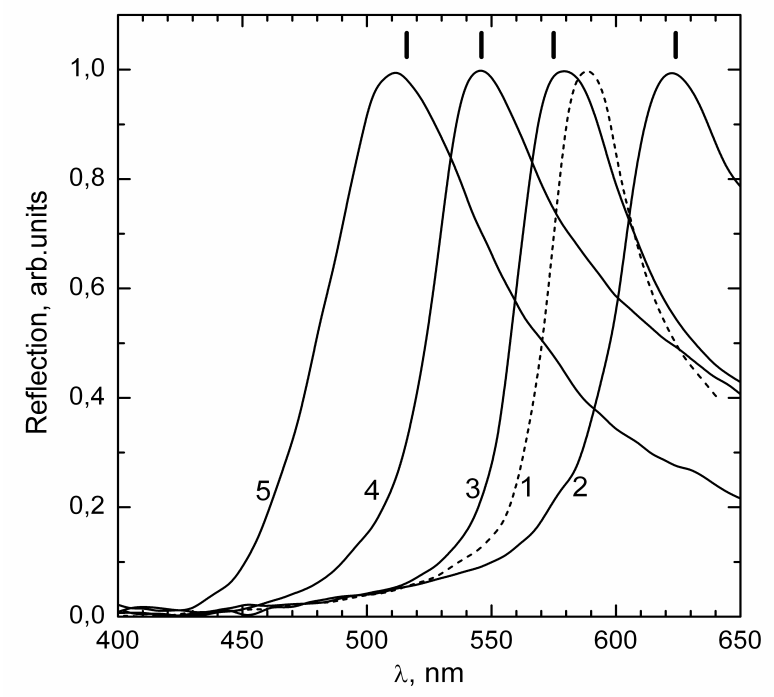

Fig. 1. Normalized reflection spectrum for the initial synthetic opal at the incidence angle $\theta=7^{\circ}$ (curve 1) and the same spectra measured after infiltrating with BBHQ: the incidence angles $\theta$ are equal to 7 (2), 35 (3), 45 (4) and $55^{\circ}$ (5). Vertical labels indicate positions of the reflection band maximums, as calculated from Eq. (1) at $D=265 \mathrm{~nm}, \varepsilon_{\text {eff }}=2.10$ and the relevant $\theta$ values.

\subsection{The nature of fluorescence spectrum for BBHQ in its solid-phase state}

The BBHQ belongs to a class of substances that reveal an excited-state intramolecular proton transfer (ESIPT) [19]. A BBHQ molecule can exist in two tautomeric modifications. The first one has an enol structure where N...H hydrogen bonds are formed, whereas the second is characterized by a keto structure where $\mathrm{O} . . . \mathrm{H}$ interaction occurs due to proton transfer. 
In the region of $270-650 \mathrm{~nm}$, the absorption spectrum of the BBHQ in its solid-phase state consists of three bands caused by transitions to the first three excited singlet states of the enol structure (see Fig. 2). The upper arrows in Fig. 2 correspond to the transitions taking place under the fluorescence excitation used just in our experiments. A long-wavelength tail present in the absorption at 2.4-2.8 eV can be caused by availability of BBHQ molecules in which the hydrogen of hydroxyl groups is replaced with various substitutes, or some other hetero-atom is present in the benzazole ring [20]. We will term the energy levels attributed to such 'defective' molecules as impurity levels (see Fig. 2).

The fluorescence spectra of the BBHQ molecules in different solvents involve two bands, with their maxima being located in the 'blue' (410-440 nm) and 'red' (570-600 nm) regions. The 'blue' fluorescence is caused by the transition occurring from the excited state to the ground state of the molecule having the enol structure. The mechanism resulting in the 'red' fluorescence is as follows. The BBHQ molecule excited at first in its enol structure undergoes a transition to the excited state of the keto structure due to proton transfer and, afterwards, it reveals a radiative transition to the ground state of its keto structure, with a following nonradiative relaxation to the ground state peculiar for the enol structure [19]. In addition to the 'blue' and 'red' fluorescences, we have observed two different bands in the $480-560 \mathrm{~nm}$ region of the fluorescence measured for the hexane-BBHQ and heptane-BBHQ solutions. Most probably, these bands are caused by the radiative transitions from the impurity levels mentioned above. Indeed, as shown in the work [20], any conversion of hydrogen from the hydroxyl group (or that occurring with the whole hydroxyl group) in the BBHQ structure into the corresponding ethers or esters, including carbonate ones, would result in noticeable shifts of the 'red' fluorescence band towards 'yellow' or 'green' spectral regions.

The fluorescence spectrum of the BBHQ in its solid-phase state observed under ultraviolet excitation is different from the spectra typical for the BBHQ in solutions. The former consists of an intense band located at 580-640 $\mathrm{nm}$ (with a maximum at about $600 \mathrm{~nm}$, i.e. $\sim 2.1 \mathrm{eV}$ ), and a broad, slightly structured band located at $460-560 \mathrm{~nm}(2.2-2.7 \mathrm{eV}$ - see curve 2 in Fig. 2). Let us involve the literature data available for the luminescence of ESIPT substances [21] in our analysis. Then the first band mentioned, which has also been observed earlier in the fluorescence spectra of the polycrystalline BBHQ [22], may be confidently attributed to the radiative transitions happening in the keto structure. The second one may be assigned to luminescence from the impurity levels, quite similar to the case of BBHQ in solutions. The reason for the latter suggestion is a presence of fluorescence bands at $460-560 \mathrm{~nm}$ in the spectra of both hexane-BBHQ and heptane-BBHQ solutions, as well as of the BBHQ in its solid-phase state. These bands are laserexcited by the wavelength of $532 \mathrm{~nm}$, i.e. far from the fundamental absorption bands in the BBHQ [23]. To confirm further the impurity nature of the luminescence, the BBHQ powder was vacuumsublimed at $2 \cdot 10^{-5} \mathrm{~mm} \mathrm{Hg}$ pressure $\left(320^{\circ} \mathrm{C}\right)$ for $2 \mathrm{~h}$. After this procedure, the relative fluorescence intensity in the spectral region mentioned above has decreased four times (cf. curves 2 and 3 in Fig. 2).

Thus, there are two mechanisms for the fluorescence occurring under excitation of the polycrystalline BBHQ powder within the fundamental absorption region. The first one, which is dominant, is a transition to the excited state of the keto structure through the proton transfer processes, with the following emission of photons with the average energy of about $2.1 \mathrm{eV}$. The second one is nonradiative relaxation of the excited enol structure to the impurity levels formed by the BBHQ molecules with substituted hydroxyl groups or modified benzazole rings. The latter 
effect is accompanied by the emission of photons with the energies $2.2-2.7 \mathrm{eV}$ (see Fig. 2). We should also note that the shape of the fluorescence spectrum typical for polycrystalline BBHQ does not depend on the specific fundamental absorption band in which the excitation is provided in our experiments.
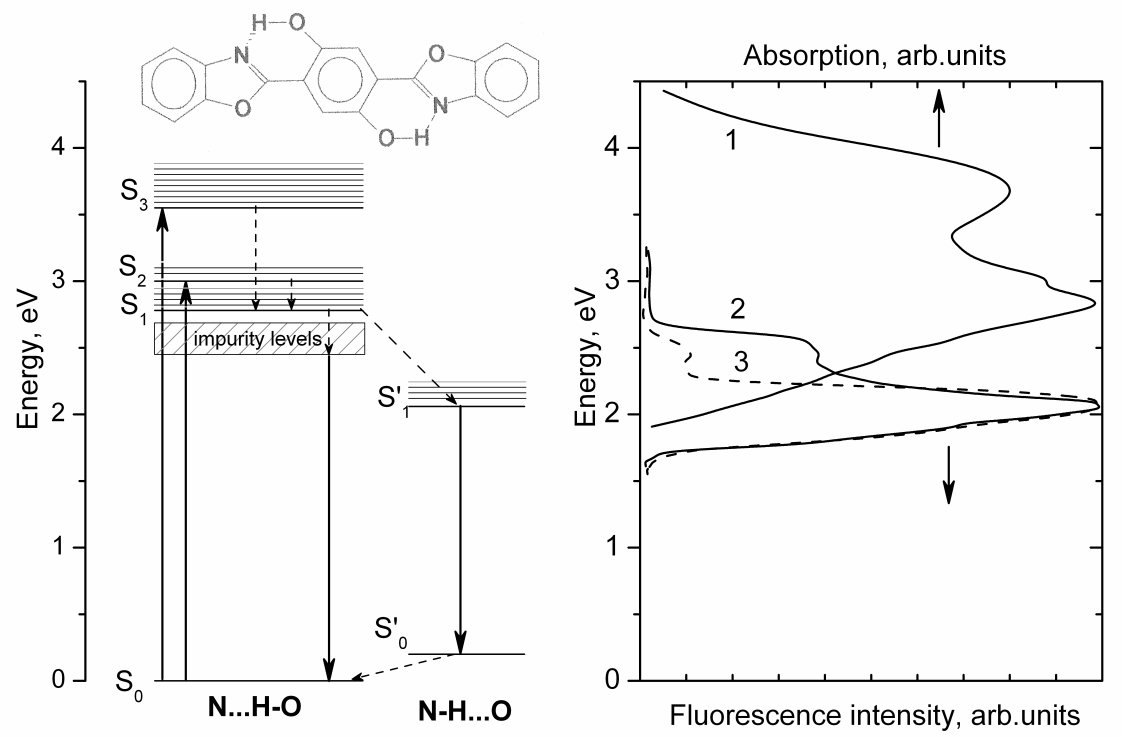

Fig. 2. Structure of the BBHQ molecule and energy diagram of the electronic states for BBHQ in its solid-phase state, with indication of possible transitions (left panel). This energy diagram is built basing on the absorption (curve 1) and fluorescence (curves 2 and 3 ) spectra measured for polycrystalline BBHQ (right panel). Ground state of the enol structure of BBHQ is taken for a zero energy level and dashed arrows correspond to nonradiative transitions. Notice that the absorption and fluorescence spectra are normalized to their maximum values and the fluorescence is excited by a $337 \mathrm{~nm}$ nitrogen laser radiation.

\subsection{Fluorescence spectra of BBHQ embedded in the pores of synthetic opal}

Under excitation at different absorption bands, the BBHQ embedded in the pores of opal matrix reveals slightly different fluorescence spectra (see curves 1 and 2 in Fig. 3). The difference is due to additional contribution of intrinsic emission of the opal matrix available under excitation with shorter wavelengths (e.g., $337 \mathrm{~nm}$ ) [24]. For avoiding this emission, we have performed our further measurements with the $407 \mathrm{~nm}$ excitation.

The fluorescence spectra typical for the BBHQ embedded in the opal matrix pores and for its polycrystalline powders are quite different. For the 'opal-BBHQ' system, we observe a 'blue' shift of the band located at $580-640 \mathrm{~nm}$ and a significant increase in the fluorescence intensity occurring at 440-550 nm for the case of light propagation direction [111] (see Fig. 3). The reasons for the 'blue' shift are partial suppression of spontaneous emission inside the stop-band (605-650 nm) and accumulation of shorter-wavelength radiation in a sample due to multiple reflections from the system of $\{111\}$ planes, which takes place at larger incidence angles [9]. With increasing 'viewing angle' $\theta$, the spectral region where the emission is suppressed follows the stop-band position determined by us from the reflection spectra (see Fig. 1 and Fig. 3). When the stop-band shifts towards shorter wavelengths as much as possible $\left(470-550 \mathrm{~nm}\right.$ at $\left.\theta=55^{\circ}\right)$, the shape of the fluorescence spectrum in the region of $580-640 \mathrm{~nm}$ is restored, and the maxima of the 'red' fluorescence bands for both the 'opal-BBHQ' system and the polycrystalline BBHQ powder again coincide (see curves 5 and 6 in Fig. 3). Incomplete character of the suppression of spontaneous 
emission inside the stop-band is caused by the optical states arising in this region due to existence of structural defects (e.g., vacancies or packing defects) and disordering in the initial opal samples.

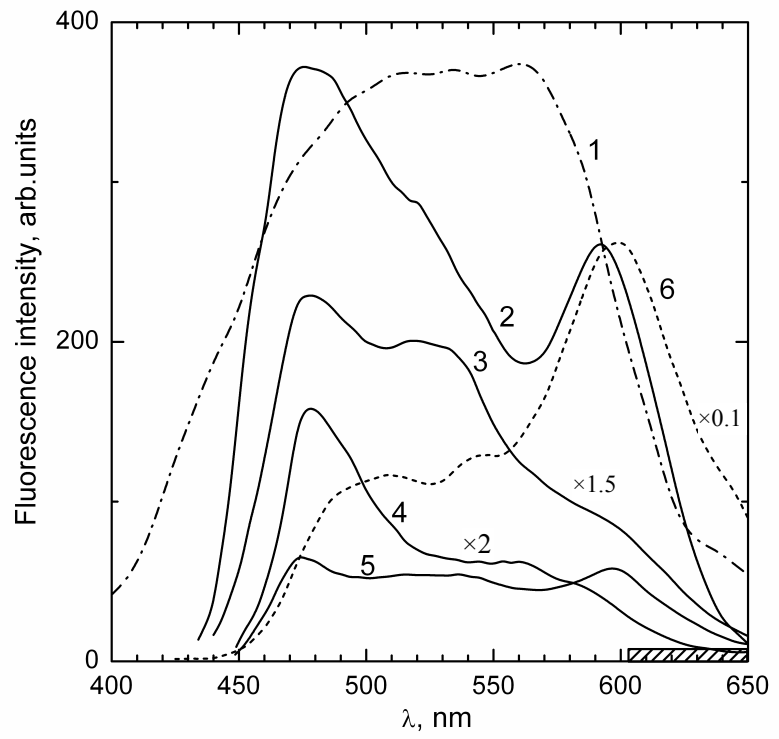

Fig. 3. Fluorescence spectra of BBHQ in the pores of synthetic opal measured at the angle $\theta=0^{\circ}$ with respect to the direction [111] under excitation with $337 \mathrm{~nm}$ (curve 1), and at the angles $\theta=0$ (2), 35 (3), 45 (4) and $55^{\circ}$ (5) under $407 \mathrm{~nm}$ excitation. Curve 6 corresponds to fluorescence spectrum for the polycrystalline BBHQ powder measured under a $407 \mathrm{~nm}$ excitation. A shaded rectangle indicates position of the stop-band for the [111] direction.

A significant increase in the fluorescence intensity happening in the region of $440-550 \mathrm{~nm}$ cannot be explained entirely by accumulation of short-wavelength radiation corresponding to the 'red' fluorescence band, and increased probability of radiation due to higher densities of optical states [4]. These factors remain crucial only close to the high-frequency edge of the stop-band, which corresponds to $560-605 \mathrm{~nm}$ at $\theta=0^{\circ}$ in our case. Hence, at least a portion of the increased fluorescence intensity at $440-550 \mathrm{~nm}$ for the 'opal-BBHQ' system may be connected with some other processes. Considering the above interpretation for the fluorescence in polycrystalline BBHQ, one can assume first of all that the luminescence through the impurity levels becomes more intense when the BBHQ is placed into a restricted volume of pores, which have the average linear sizes as small as about $70 \mathrm{~nm}$. On the other hand, filling in of opals starts from forming of BBHQ on the surface of $\mathrm{SiO}_{2}$ globules. This results in appearance of surface states in the energy spectrum. Under condition of restricted volume of a substance inside the opal pores, the number of BBHQ molecules available on the surfaces of globules is larger than that in the volume of the pores. Consequently, the importance of transitions involving the surface states may become higher than that of $S_{1}^{\prime} \rightarrow S_{0}^{\prime}$ transitions, which give rise to the 'red' fluorescence band (see Fig. 2).

\section{Conclusion}

We have estimated the effective dielectric constant for the 'opal-BBHQ' system, basing on angular dependences of the reflection spectra. In what the fluorescence of polycrystalline BBHQ is concerned, the process of photon emission from the excited state of the keto structure dominates over the luminescence through the impurity levels, which correspond to BBHQ molecules with substituted hydroxyl groups or modified benzazole rings. In the fluorescence spectrum studied for 
the 'opal-BBHQ' system, we observe a suppression of the emission inside the stop-band and a significant increase in the luminescence intensity in the region of $440-550 \mathrm{~nm}$. A luminescence through the impurity levels and a higher role of radiative transitions through the surface states may be the reasons for the latter fact. Domination of the both mechanisms in the emission from the excited state of the keto structure becomes possible when the volume in which the BBHQ is packed inside the opal pores gets restricted. Finally, we notice that the regularities observed in this work can enable new techniques for controlling radiative processes in the substances placed into the pores of the opal matrix.

\section{Acknowledgments}

This work was supported by the joint Ukrainian-Russian projects "Creation and investigation of active matrix nanocomposites on the base of photonic glasses and crystals for solar cells" and "Development of new materials on the basis of photonic crystals for nanobiophotonics and investigation of its optical properties".

\section{References}

1. Joannopoulos J, Johnson G, Winn J and Meade R. Photonic crystals. Molding the flow of light. Princeton and Oxford: Princeton University Press (2008).

2. Yablonovitch E, 2007. Photonic crystals: what's in a name? Opt. Photonics News. 183: 12-13.

3. Yablonovitch E, 1987. Inhibited spontaneous emission in solid-state physics and electronics. Phys. Rev. Lett. 58: 2059-2062.

4. Vats N, John S and Bush K, 2002. Theory of fluorescence in photonic crystals. Phys. Rev. A. 65: 043808.

5. Sinitskii A, Knot'ko A and Tretyakov Yu, 2004. Silica photonic crystals: synthetis and optical properties. Sol. State Ionics 172: 477-479.

6. Gaponenko S, Bogomolov V, Petrov E, Kapitonov A, Yarotsky D, Kalosha I, Eychmueller A, Rogach A, McGilp J, Woggon U and Gindele F, 1999. Spontaneous emission of dye molecules, semiconductor nanocrystals, and rare-earth ions in opal-based photonic crystals. J. Lightwave Technol. 17: 2128-2137.

7. Megens M, Wijnhoven J, Lagendijk Ad and Vos W, 1999. Light sources inside photonic crystals. J. Opt. Soc. Amer. B. 16: 1403-1408.

8. Aliev G, Golubev V, Dukin A, Kurdyukov D, Medvedev A, Pevtsov A, Sorokin L and Hutchison J, 2002. Structural, photonic band-gap, and luminescence properties of the opalerbium composite. Phys. Sol. State. 44: 2224-2231.

9. Bechger L, Lodahl P and Vos W, 2005. Directional fluorescence spectra of laser dye in opal and inverse opal photonic crystals. J. Phys. Chem. B. 109: 9980-9988.

10. Gruzintsev A, Emel'chenko G, Masalov V, Yakimov E, Barthou C and Maitre A, 2009. Luminescence of $\mathrm{CdSe} / \mathrm{ZnS}$ quantum dots infiltrated into an opal matrix. Semiconductors. 43: 197-201.

11. Gruzintsev A, Emel'chenko G and Masalov V, 2009. Photoluminescence of $\mathrm{ZnO}$ infiltrated into a three-dimensional photonic crystal. Semiconductors. 43: 1017-1022.

12. Kim S, Park S, Kwon J and Park S Y, 2011. Organic light-emitting diodes with a whiteemitting molecule: emission mechanism and device characteristics. Adv. Funct. Mater. 21: 644-651.

13. Sakai K, Tsuzuki T, Itoh Y, Ichikawa M and Taniguchi Y, 2005. Using proton-transfer laser dyes for organic laser diodes. Appl. Phys. Lett. 86: 081103.

Ukr. J. Phys. Opt. 2013, Volume 14, Issue 4 
14. Uzhinov B and Druzhinin S, 1998. Excited state proton transfer dye lasers. Russ. Chem. Rev. 67: $123-136$.

15. Kocher C, Weder C and Smith P, 2003. "Latent" ultraviolet light absorbers. J. Mater. Chem. 13: $9-15$.

16. Moiseyenko V, Guziy O, Gorelik V and Dergachov M, 2008. Optically excited secondary emission spectra of photonic crystals based on synthetic opals. Opt. Spectr. 105: 919-923.

17. Stöber W, Fink A and Bohn E, 1968. Controlled growth of monodisperse silica spheres in micron size range. J. Coll. Inter. Sci. 26: 62-68.

18. Baryshev A, Kaplyanskii A, Kosobukin V, Limonov M, Samusev K and Usvyat D, 2003. Bragg diffraction of light in synthetic opals. Phys. Sol. State. 45: 459-471.

19. Mordzinski A, Grabowska A and Teuchner K, 1984. Mechanism of excited-state proton transfer in "double" benzoxazoles: 2,5-bis(2-benzoxazolyl)hydroquinone. Chem. Phys. Lett. 111: $383-388$.

20. Orlando C, Wirth J and Heath D, 1972. 2,5-bis(2-benzoxazolyl)hydroquinones and their derivatives. US Patent 3673202.

21. Mordzinski A, Excited state intramolecular proton transfer: the structural and dynamical aspects. Institute of Physical Chemistry PAN: Warszaw (1990).

22. Orlando CM, Wirth JG and Heath DR, 1971. Red- and near-infrared luminescent benzazole derivatives. J. Chem. Soc. D. 1551b-1552.

23. Chayka K, Moiseyenko V and Mordzinski A, 2005. Luminescence of 2,5-bis(2-benzoxazolyl)hydroquinone molecules adsorbed on copper island film. Ukr. J. Phys. Opt. 5: 128-132.

24. Gorelik V, 2007. Optics of globular photonic crystals. Quant. Electron. 37: 409-432.

Moiseyenko V., Dergachov M., Abu Sal B. and Yevchik A. 2013. Modification of optical properties of 2,5-bis(2-benzoxazolyl)hydroquinone in opal photonic crystals. Ukr.J.Phys.Opt. 14: $225-232$

Анотація. У роботі досліджено кутову залежність спектрів відбивання та флюоресцениії синтетичного опалу, інфільтрованого фотореактивною речовиною - 2,5-біс(2-бензоксазоліл) гідрохіноном (ВBHQ). Зсув максимуму спектра відбивання зі зростанням кута падіння світла добре описується дифракційним співвідношенням Брепта, якщо значення ефективної діелектричної проникливості отриманого композиту дорівнює $\varepsilon_{\text {eff }}=2.10$. Виявлено пригнічення флюоресиениії в межах стоп-зони та зростання інтенсивності для більш короткохвильової флюоресценції. Ефект пояснено зростанням ролі випромінювальних переходів через поверхневі стани та домішкові рівні. Концентрація поверхневих станів для ВBHQ у порах опалу суттєво збільшується, а домішкові рівні утворюються молекулами ВBHQ із заміщеними гідроксильними групами або із модифікованими бензазольними кільиями. 